\title{
Towards microalgal triglycerides in the commodity markets
}

\author{
Giulia Benvenuti ${ }^{1 *}$,, Jesús Ruiz ${ }^{2}$, Packo P. Lamers ${ }^{1}$, Rouke Bosma ${ }^{1}$, René H. Wijffels ${ }^{1,3}$ and Maria J. Barbosa ${ }^{1}$
}

\begin{abstract}
Background: Microalgal triglycerides (TAGs) hold great promise as sustainable feedstock for commodity industries. However, to determine research priorities and support business decisions, solid techno-economic studies are essential. Here, we present a techno-economic analysis of two-step TAG production (growth reactors are operated in continuous mode such that multiple batch-operated stress reactors are inoculated and harvested sequentially) for a 100-ha plant in southern Spain using vertically stacked tubular photobioreactors. The base case is established with outdoor pilot-scale data and based on current process technology.

Results: For the base case, production costs of $6.7 €$ per $\mathrm{kg}$ of biomass containing $24 \%$ TAG (W/W) were found. Several scenarios with reduced production costs were then presented based on the latest biological and technological advances. For instance, much effort should focus on increasing the photosynthetic efficiency during the stress and growth phases, as this is the most influential parameter on production costs (30 and 14\% cost reduction from base case). Next, biological and technological solutions should be implemented for a reduction in cooling requirements (10 and 4.5\% cost reduction from base case when active cooling is avoided and cooling setpoint is increased, respectively). When implementing all the suggested improvements, production costs can be decreased to $3.3 €$ per $\mathrm{kg}$ of biomass containing 60\% TAG (w/w) within the next 8 years.

Conclusions: With our techno-economic analysis, we indicated a roadmap for a substantial cost reduction. However, microalgal TAGs are not yet cost efficient when compared to their present market value. Cost-competiveness strictly relies on the valorization of the whole biomass components and on cheaper PBR designs (e.g. plastic film flat panels). In particular, further research should focus on the development and commercialization of PBRs where active cooling is avoided and stable operating temperatures are maintained by the water basin in which the reactor is placed.
\end{abstract}

Keywords: Microalgae, Triglyceride production, Techno-economic analysis, Production costs

\section{Background}

Currently, microalgal products are mainly sold in niche markets [1]. Commercially relevant microalgal products are basically biomass or extracts rich in PUFAs (EPA, DHA), essential amino acids and antioxidants (carotenoids, tocopherols and phenols) as supplements for human health and cosmetics [2,3]. However, in the last 10 years, industry has been looking at alternative and sustainable feedstocks for commodities in the food, feed, chemical and biofuel sectors. This is mainly due to

\footnotetext{
*Correspondence: giuliabenvenuti@alice.it

1 Bioprocess Engineering, AlgaePARC, Wageningen University,

P.O. Box 16, 6700 AA Wageningen, The Netherlands

Full list of author information is available at the end of the article
}

the social and political awareness for sustainability, the instability of fossil fuel prices, the pressure on agriculture crops for non-food applications, the growth in population and limited availability of arable land. In this context, microalgal triglycerides (TAGs) are regarded as an attractive source to supplement or substitute oils derived from fossil resources and/or agricultural crops [4, 5]. Microalgae can grow on non-arable land and they have a low freshwater and fertilizer footprint when grown on wastewater, sea- or brackish water [4]. Besides TAGs, other valuable products are obtained [6], improving the range of marketable products and consequently the commercial feasibility. A commercial microalgal bulk industry would represent an enormous incentive for national 
economies. Malik et al. [7] calculated that the production of 1 Mton of bio-crude oil from microalgae could generate 13,000 new jobs in Australia and turnover of 2.6 billion $€$. Despite the high potential of microalgae as sustainable TAG cell factories, microalgal TAGs are not yet commercialized, mainly due to process immaturity and estimated high production costs [8].

To determine research priorities and support business decisions, solid techno-economic studies are essential. Although several studies have been published on N-replete biomass [8-10], only a few specifically focus on processes targeted to the production of TAGenriched biomass under so-called "stress" conditions (e.g. $\mathrm{N}$-starvation).

Here, we present projection on a two-step 100-hascale TAG production process in which, in the first step, biomass is grown under nitrogen replete conditions in continuously operated photobioreactors ("growth" PBRs) and, in the second step, multiple batch-operated stress (i.e. nitrogen starvation) PBRs are inoculated and sequentially harvested, thus ensuring a daily harvest of TAG-enriched biomass. Noteworthy, in our study, photosynthetic efficiencies obtained in outdoor pilot cultivations of Nannochloropsis sp. CCAP 211/78 [11, 12] are used as model input to conduct the techno-economic analysis for the mentioned production facility. Furthermore, our study considers location-specific parameters such as climate, labour and energy costs, which highly affect productivity and economic profitability. The production costs of TAG-enriched biomass are presented based on current process technology. Finally, a sensitivity analysis is performed and scenarios with reduced production costs are discussed in the light of the latest biological and technological advances, indicating the roadmap towards a further cost reduction.

\section{Methods}

In the following section, a techno-economic analysis of a two-step TAG production is presented and used as basis to indicate guidelines for future research. The solid techno-economic model originally developed by Ruiz et al. [13] for nitrogen replete biomass production was extended with the TAG production phase. Our evaluation includes the cultivation phase in "growth" and "stress" PBRs and the biomass concentration step to obtain $15 \% \mathrm{w} / \mathrm{w}$ algal slurry as final product. The production costs of TAG-enriched biomass are presented.

In our process, nitrogen $(\mathrm{N})$ replete biomass is produced in continuous (chemostat)-operated PBRs ("growth PBRs") to ensure a continuous supply of inoculum for the TAG accumulation phase for which multiple batch-operated "stress PBRs" are sequentially inoculated and harvested at maximum time-averaged
TAG productivity [14] ensuring a constant daily harvest of TAG-enriched biomass (Additional file 1: Fig. A1). Projections were made for a 100-ha-scale plant using vertically stacked tubular PBRs in southern Spain $\left(37^{\circ} 15^{\prime}\right.$ $\left.\mathrm{N} 6^{\circ} 56^{\prime} \mathrm{W}\right)$. The design of the PBRs is identical to the vertically stacked horizontal tubular photobioreactors described by [13].

\section{Process description}

The production area (100 ha) is divided into two stages: the growth phase, where biomass is produced in chemostat-operated PBRs, and the stress phase, producing TAG-enriched biomass in batch-operated PBRs under nitrogen starvation (Fig. 1).

The process starts by filtering natural seawater from the surface, which is then mixed with nutrients in an automatized mixing unit and pumped into the growth PBRs. The seawater-based medium enters the growth PBRs only during daylight hours, and, concurrently, the same culture volume leaves the reactors. This outflow sequentially fills different stress PBRs to which no nutrients are added to promote TAG accumulation. Culture medium is enriched with different nutrients [12] but only the cost of nitrogen, phosphorus and $\mathrm{CO}_{2}$ is considered being those with major influence on economics [13].

In each stress PBR unit, the TAG accumulation phase starts immediately after inoculation. For this, it is assumed that the culture leaving the growth PBRs is free of extracellular nitrogen source with no impact on the biomass productivity. In practice, a near-zero extracellular nitrogen concentration can be achieved by adopting nitrogen sensors, turbidity sensors (using an empirically determined nitrogen content of biomass) or off-gasbased dosing (using empirical stoichiometric relations).

In the stress phase, independent PBR units are harvested sequentially, resulting in a batch strategy with a certain retention time. Thus, from the entire stress area there is a constant daily harvest of TAG-enriched biomass. When the stress PBRs are harvested, the TAGenriched biomass is pumped into the centrifuge where $15 \%$ algal slurry is obtained. In both growth and stress PBRs, the culture is mixed by a recirculation pump at a horizontal liquid velocity in the tubes of a flow of $0.45 \mathrm{~m} \mathrm{~s}^{-1}$, typically used in this type of photobioreactor [11]. The culture is supplied with pure $\mathrm{CO}_{2}$ on demand to keep $\mathrm{pH}$ at the set point of 7.5 [12]. To prevent oxygen inhibition, degassers ensure that oxygen partial pressure never exceeds $300 \%$ [15], equivalent to three times saturation with respect to air.

Culture temperature is maintained below $30{ }^{\circ} \mathrm{C}$ with heat exchangers that recirculate seawater from a depth of $200 \mathrm{~m}$. Wastewater treatment is not performed because the effluent of the stress PBRs is considered free of 


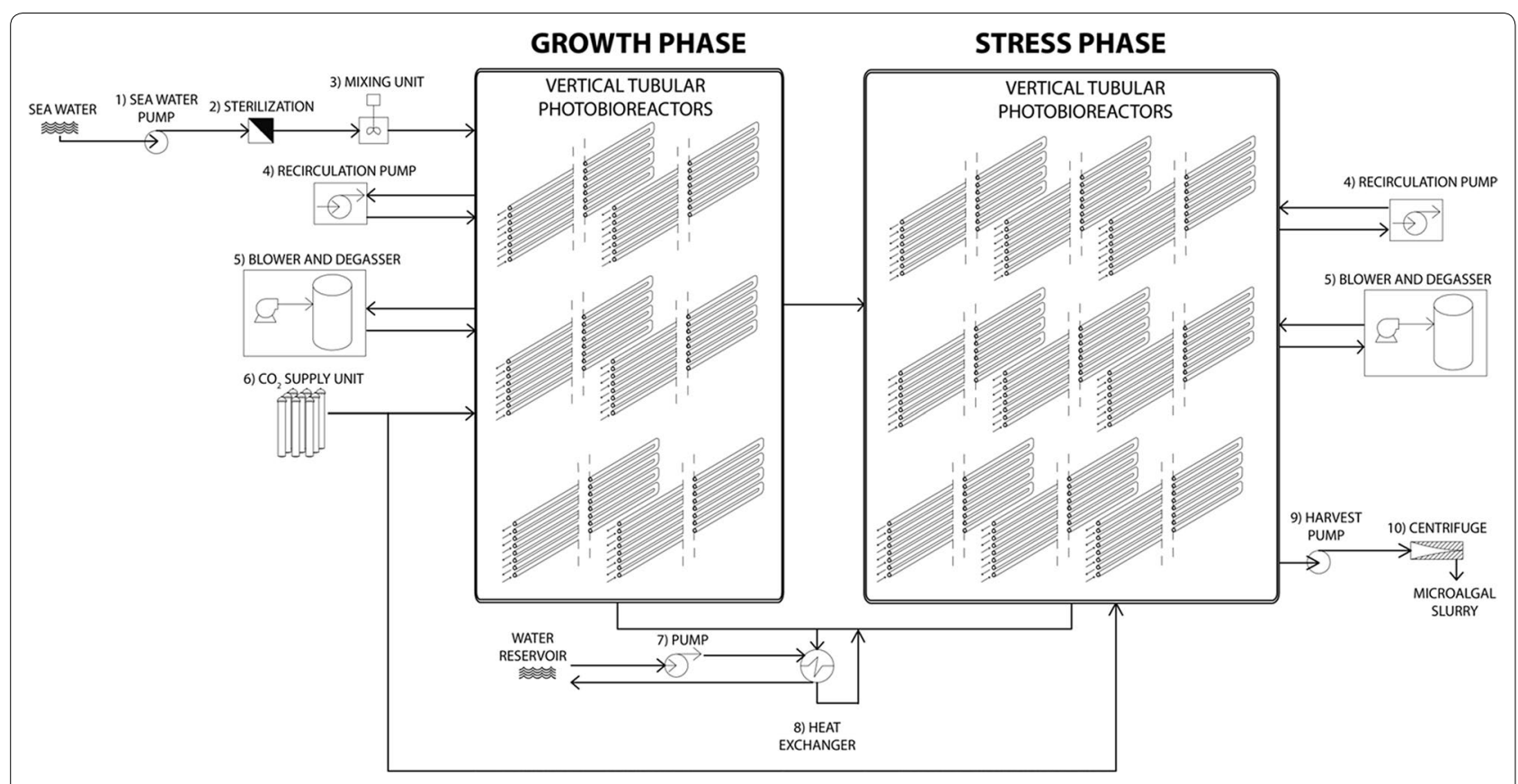

Fig. 1 Plant configuration. Schematic representation of the plant as adopted for the base case projection (see "Process description")

nutrients and organic matter. The plant is operational for 300 days per year, three cleanings per year are performed and one plant manager, three supervisors and 28 operators are required to run the facility [13].

\section{Empirical data and area allocation}

For the base case, yearly biomass and TAG productivities were calculated using the photosynthetic efficiencies (i.e. fraction of total light energy converted into chemical energy during photosynthesis) obtained outdoors at AlgaePARC pilot facility in the Netherlands ([11] for biomass production and [12] for TAG production) and the total irradiance in southern Spain [13] (Additional file 1: Eq. A1). For the growth phase, an average photosynthetic efficiency of $2.17 \%$ for biomass production (containing $4 \%$ TAG $\mathrm{w} / \mathrm{w}$ ) and a daily culture dilution rate of $27 \%$ were used [11]. This means 3.7 days of retention time of culture in growth phase. For the stress phase, an average photosynthetic efficiency of $1.48 \%$ for biomass production (containing 24\% TAG w/w) was used (Additional file 1: Table A1; [12]). Based on the data obtained at pilot scale in the Netherlands [11, 12], we calculated that under low-light conditions in the Netherlands $\left(14 \mathrm{~mol} \mathrm{~m}^{-2} \mathrm{~d}^{-1}\right)$, total TAG productivity is maximal after 9 days in the stress reactor, whereas at high-light conditions ( $36 \mathrm{~mol} \mathrm{~m}^{-2} \mathrm{~d}^{-1}$ ), the productivity is maximal after 6 days. Because southern Spain has longer periods of high light compared to the Netherlands, we chose to always harvest the TAG-enriched biomass after 6 days in the stress PBRs. This retention time of 6 days can thus be regarded as a $17 \%$ daily dilution of the PBRs in the stress area.

The total production area (100 ha) was allocated between growth and stress phase using mass balances based on total area and the aforementioned dilution rates. It resulted in areas of 38.2 and 61.8 ha and volumes of 21,014 and $33,700 \mathrm{~m}^{3}$ for the growth and stress phases, respectively. $10 \%$ of the growth area is allocated to inoculum production to fill the growth PBRs after a routine cleaning or culture crash. The area for inoculum production is considered identical to the growth area in terms of operational and capital costs (OPEX and CAPEX). However, since this biomass is only incidentally transferred to the growth PBRs, the inoculum production area is assumed as non-productive. The area occupied by side equipment and piping is considered as $20 \%$ of the production area, thus resulting in a total facility area of 120 ha.

As described by Ruiz et al. [13], the model uses location-specific parameters such as climatic conditions, energy costs (Additional file 1), labour costs and employer's contribution to labour costs as well as workweek hours (Additional file 1: Table A5). In Additional file 1: Table A2, the changes in major equipment (numbers 1-11 in Fig. 1), capacity and power requirement are reported. These modifications were made due to the different process strategy adopted in this study (i.e. different area, flows and volumes) compared to Ruiz et al. 
[13]. Furthermore, in Additional file 1: Table A3, the procedure for calculating CAPEX and OPEX is reported. An account of the main model features is given in Additional file 1. For further details, we refer to [13].

\section{Results}

Production cost of TAG-enriched biomass: base case based on pilot plant data

The photosynthetic efficiencies and TAG contents obtained at pilot scale using current process technology and design were used as model base case (Table 1). A
TAG-enriched biomass production cost of $6.7 € \mathrm{~kg}^{-1}$ was obtained and the net energy ratio (energy produced as dry microalgae biomass/energy consumed as electricity) was 1.1. The latter indicates that the amount of energy (i.e. chemical energy; Additional file 1: Table A1) generated by the process was slightly higher than the energy required for operating the plant to obtain the algal slurry.

A cost breakdown analysis was conducted (Fig. 2). Our analysis shows that, in both phases, the largest contribution to total costs (35\% for growth and $27 \%$ for stress) is given by construction and other fixed costs (i.e. land

Table 1 Results of the techno-economic analysis

\begin{tabular}{|c|c|c|}
\hline & $\begin{array}{l}\text { Base case } \\
\text { Growth phase: } 2.17 \% \mathrm{PE}, 4 \% \mathrm{TAG} w / \mathrm{w} \\
\text { Stress phase: } 1.48 \% \mathrm{PE}, 24 \% \mathrm{TAG} \mathrm{w} / \mathrm{w} \\
30^{\circ} \mathrm{C} \text { max. culture temperature for cooling } \\
\text { Current process technology }\end{array}$ & $\begin{array}{l}\text { Optimized case (1) in Fig. 4) } \\
\text { Growth phase: } 6 \% \mathrm{PE}, 4 \% \text { TAG w/w } \\
\text { Stress phase: } 4.10 \% \mathrm{PE}, 60 \% \mathrm{TAG} \text { w/w } \\
40{ }^{\circ} \mathrm{C} \text { max. culture temperature for cooling } \\
\text { Optimized process technology* }\end{array}$ \\
\hline Total costs $\left(M €\right.$ year $\left.^{-1}\right)$ & 25.6 & 28.2 \\
\hline Biomass production (Kton year ${ }^{-1}$ ) & 3.8 & 8.7 \\
\hline TAG production (Kton year ${ }^{-1}$ ) & 0.5 & 3.7 \\
\hline Biomass cost $\left(€ \mathrm{~kg}^{-1}\right)$ & 6.7 & 3.3 \\
\hline CAPEX $\left(M €\right.$ year $\left.^{-1}\right)$ & 9.7 & 14.4 \\
\hline OPEX $\left(M €\right.$ year $\left.^{-1}\right)$ & 16.0 & 13.9 \\
\hline Initial investment $(\mathrm{M} €)$ & 140.8 & 210.1 \\
\hline Produced energy (GWh year ${ }^{-1}$ ) & 26.0 & 70.9 \\
\hline Consumed energy $\left(G W h\right.$ year ${ }^{-1}$ ) & 22.8 & 38.0 \\
\hline Net energy ratio & 1.1 & 1.9 \\
\hline
\end{tabular}

* Flow velocity is reduced from 0.45 to $0.3 \mathrm{~m} \mathrm{~s}^{-1}$ during the day and to $0.23 \mathrm{~m} \mathrm{~s}^{-1}$ during the night. Harvest is performed by pre-concentration of the biomass by microfiltration followed by centrifugation instead of using centrifugation only; flue gas is used as $\mathrm{CO}_{2}$ source instead of commercial $\mathrm{CO}_{2} ; 310$ operational days per year instead of 300; reduced number of employees (one manager, one supervisor, eight operators instead of one manager, three supervisors and 28 operators); cleaning reduced from three times to one per year; the fraction of the facility used to prepare inoculum is reduced from 10 to $5 \%$ of the growth area

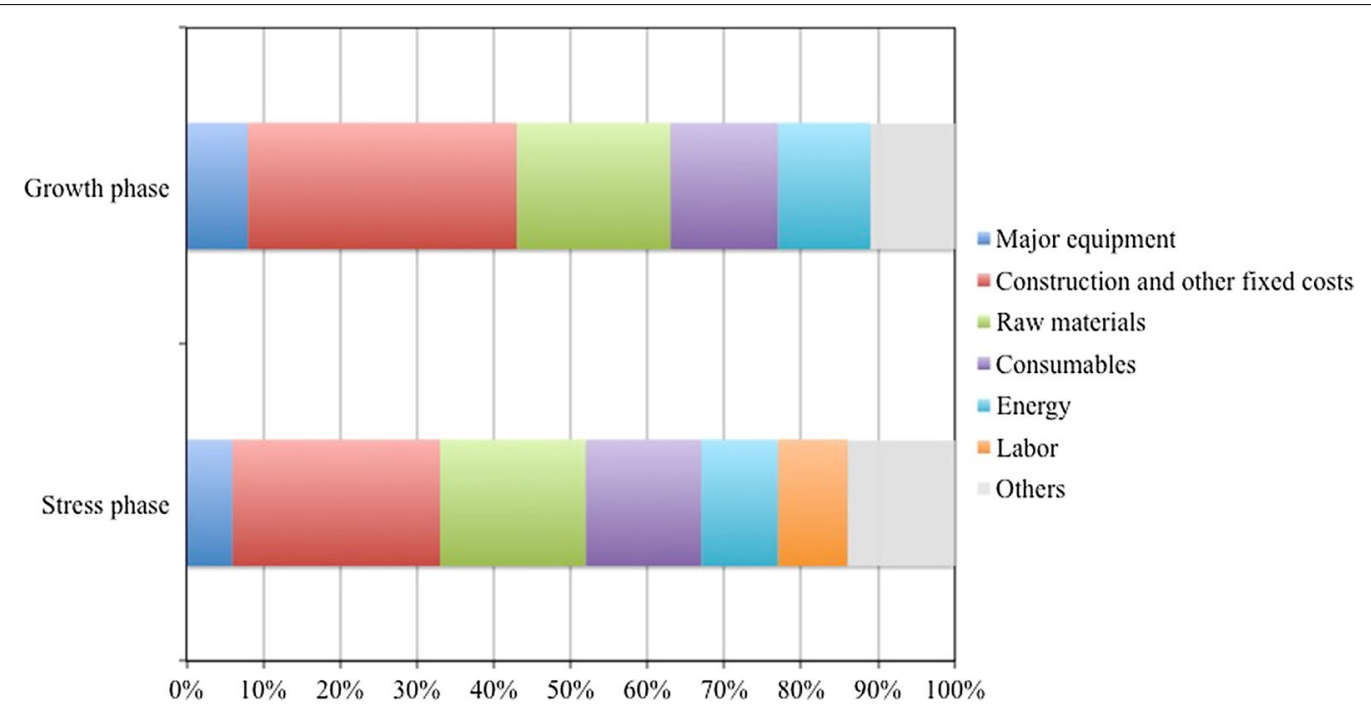

Fig. 2 Cost breakdown. Cost breakdown for growth $(\mathbf{a})$ and stress $(\mathbf{b})$ phases for a two-step-continuous TAG production process in vertically stacked tubular PBRs. Labour costs of the complete facility (100 ha) are assigned to the stress phase to simplify calculations 
improvement, installation costs, service facilities, instrumentation and control, electrical, piping, buildings, construction expenses, engineering and supervision, contractor's fee, contingency), followed by raw materials (i.e. nutrients as well as chemicals and granulate used for cleaning) and consumables (i.e. glass tubes).

Despite the fact that the largest contribution to total costs (35\% for growth and $27 \%$ for stress) is given by construction and other fixed costs (Fig. 2, Additional file 1: Table A3), these have not been considered in our sensitivity analysis (Fig. 3). In fact, due to the lack of large facilities ( $>5 \mathrm{ha}$ ) and the novelty of the process, a certain level of uncertainty is related to these costs. We, however, believe that with a more mature technology, construction and fixed costs can be decreased by, for instance, reducing contingencies and the capital required for instrumentation and control.

\section{Opportunities for cost reduction}

To estimate the cost reduction that expected advances in the field could yield, we performed a sensitivity analysis (Fig. 3). For a substantial cost reduction, both biological performance of the production strain and process technology should be optimized. For this, the impact of expected improvements on the production cost was investigated. The individual effect was analysed in isolation to identify key parameters. It is assumed that a single parameter change does not alter the rest of variables. Likewise, it is also presented the case where all these factors are simultaneously changed to the future value ("Implementation of all improvements" in Fig. 3 and "Optimized case" in Table 1)."

We consider some of the below-mentioned improvements that are feasible in the short term (within the next 3 years from now) and some in the mid-term (within the next 8 from now).

\section{Short-term improvements}

- The flow velocity is reduced from 0.45 to $0.3 \mathrm{~m} \mathrm{~s}^{-1}$ during the day [16] and to $0.23 \mathrm{~m} \mathrm{~s}^{-1}$ during the night (with no negative effects on productivity) [17].

- Flue gas instead of commercial $\mathrm{CO}_{2}$ is used (with no negative effects on productivity) [18].

- The plant is operational for 310 days per year instead of 300 .

- The fraction of the facility used to prepare inoculum is reduced from 10 to $5 \%$ of the growth area.

- TAG-enriched biomass is pre-concentrated by microfiltration and subsequently centrifuged. The biomass is concentrated 15 times by membrane filtration at a flow of $32 \mathrm{~L} \mathrm{~m}^{-2} \mathrm{~h}^{-1}$ [19]. The retentate is then further processed by centrifugation.

\section{Mid-term improvements}

- An increased photosynthetic efficiency (PE) has been suggested to be one of the major targets to achieve a substantial cost reduction [20,21]. During the growth phase, the PE is increased to $6 \%[13,22]$ while, for




stress phase, the PE is increased proportionally to $4.1 \%$, and the TAG content is augmented to $60 \% \mathrm{w} / \mathrm{w}$ [23]. In such a way, the combined effect of biological and process improvements on TAG productivity, as thoroughly discussed in "How to increase TAG productivity", is represented.

- The maximum culture temperature at which cooling is started is increased from 30 to $40{ }^{\circ} \mathrm{C}$. Lower cooling requirements could be achieved by selecting or improving strains that can be cultivated with the same productivity at higher culture temperatures $[24$, 25].

- Active culture cooling can be avoided in floating/ submerged cultivation systems (e.g. Algae Floating Systems, Inc., Algasol Renewables, OMEGA PBRs) placed in water bodies close to land or in shallow (artificial) basins in which seawater can be introduced and released based on tide differences.

- Reactors are cleaned once per year instead of three, as a result of a better fouling management and robust process less prone to contamination.

- The number of employees is reduced to one manager, one supervisor and eight operators [9]. For this, high degree of automation and a more mature technology are necessary.

For future projections, the basis of the calculations was identical to the base case with the exception of scenarios (1) and (3) of Fig. 3. For these two scenarios, the photosynthetic efficiency during the growth phase was increased, while the biomass concentration was kept at the same values as in the base case. As a result, a greater dilution rate of $78.5 \%$ was used (i.e. hydraulic retention time of 1.27 days). As the flow leaving the growth area must be identical to the flow entering the stress area, the areas and volumes of both growth and stress phases were changed resulting in 17.5 and 82.5 ha and 10,052 and $45,754 \mathrm{~m}^{3}$, respectively.

With our sensitivity analysis (Fig. 3) we define a roadmap (Fig. 4) for research on microalgae TAG production. Much effort should be focused on increasing the photosynthetic efficiency (i.e. productivity) during the stress and growth phases, as this is the most influential parameter on production costs (30 and $14 \%$ cost reduction from base case) [26-28]. Next, biological and technological solutions should be implemented for a reduction in cooling requirements (10 and $4.5 \%$ cost reduction from base case when active cooling is avoided and cooling setpoint is $40^{\circ} \mathrm{C}$, respectively) (Fig. 3). The development of robust processes, which are less prone to contamination and fouling, thus requiring less cleaning, can save up to $10 \%$ compared to the base case. Similarly, reduction of labour costs can be achieved by investing on automation, thus contributing to a $6 \%$ reduction in total production costs. If all suggested improvements are combined, TAGenriched biomass production costs will be substantially reduced from 6.7 to $3.3 € \mathrm{~kg}^{-1}$ (with $60 \% \mathrm{w} / \mathrm{w}$ TAG content; Table 1).

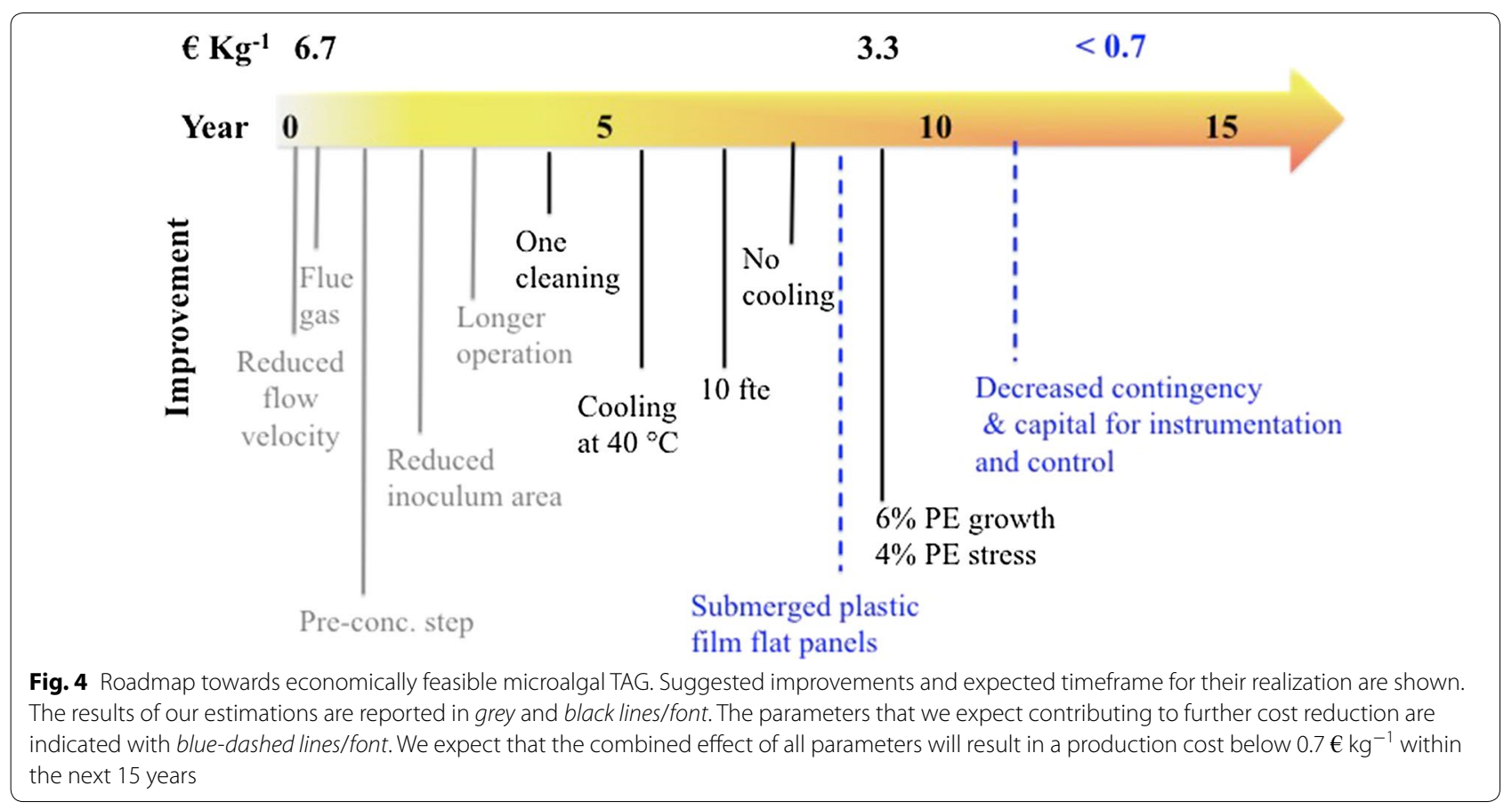


Nevertheless, to enter the commodity markets, production costs should decrease even further. Production costs should be at least lower than the selling price (0.7$3.5 € \mathrm{~kg}^{-1}$; [13]; Fig. 4). However, without a detailed market analysis, a production cost below market value is not enough to establish economic decisions. We believe that further cost reduction can be achieved when contingencies will be decreased due to a more mature technology, as well as the capital for instrumentation and control. Next, plastic film flat panels, instead of tubular systems, should be used as they are more productive, require lower installation and operational costs and produce a culture with a greater biomass concentration [13]. Active cooling should be avoided. For this, potential relies on floating/submerged cultivation systems. By joining forces in these research areas, we believe that production cost below $0.7 € \mathrm{~kg}^{-1}$ can be achieved within the next 15 years (Fig. 4).

To ensure economic viability of microalgal TAGs at the current commodity market values, the other biomass components should be valorized as well as the selling price of microalgal TAGs should be increased (e.g. enriching the TAG composition in specific fatty acids with higher market price).

\section{Discussion}

\section{How to increase TAG productivity}

Our sensitivity analysis indicates that increasing the TAG productivity is the most influential parameter on cost reduction (Fig. 3). Several approaches for increasing TAG productivity are proposed (Fig. 5). These are essentially related to the selection and/or improvement of the production strain as well as to the optimization of process conditions. In the following sections, the most relevant approaches are discussed and guidelines for improving TAG productivities are presented.

\section{Biological approach for higher TAG productivities}

Exploring the genetic diversity of microalgae Several screening studies have been performed [24, 29-35]. In practice, only few microalgae (e.g. Nannochloropsis, Chlorella, Scenedesmus, Neochloris) have been tested. However, the high genetic diversity of microalgae should be fully explored to select a robust production strain. To reduce risks of contamination, obtain stable productivities and decrease costs during cultivation (e.g. cooling, $\mathrm{pH}$ control), microalgae should be isolated from highly selective and extreme environments such as deserts, hot and alkaline-saline waters. Additionally, high-throughput screening protocols (e.g. microfluidics) [33, 36, 37] for which the target product (e.g. TAG) can be quantified [38-40] should be routinely adopted. The predictability of such high-throughput screenings should be validated at lab scale with the selected strains and processes should be developed under simulated outdoor production conditions [34]. Finally, the selected strains should be tested outdoors in pilot PBRs under relevant climate conditions $[24,41,42]$.

Strain improvement Besides the natural diversity of microalgae, strain improvement can further enhance TAG productivity. Improving carbon partitioning towards TAG production and photosynthetic efficiency are the two main targets [14, 43, 44]. Recently, successful

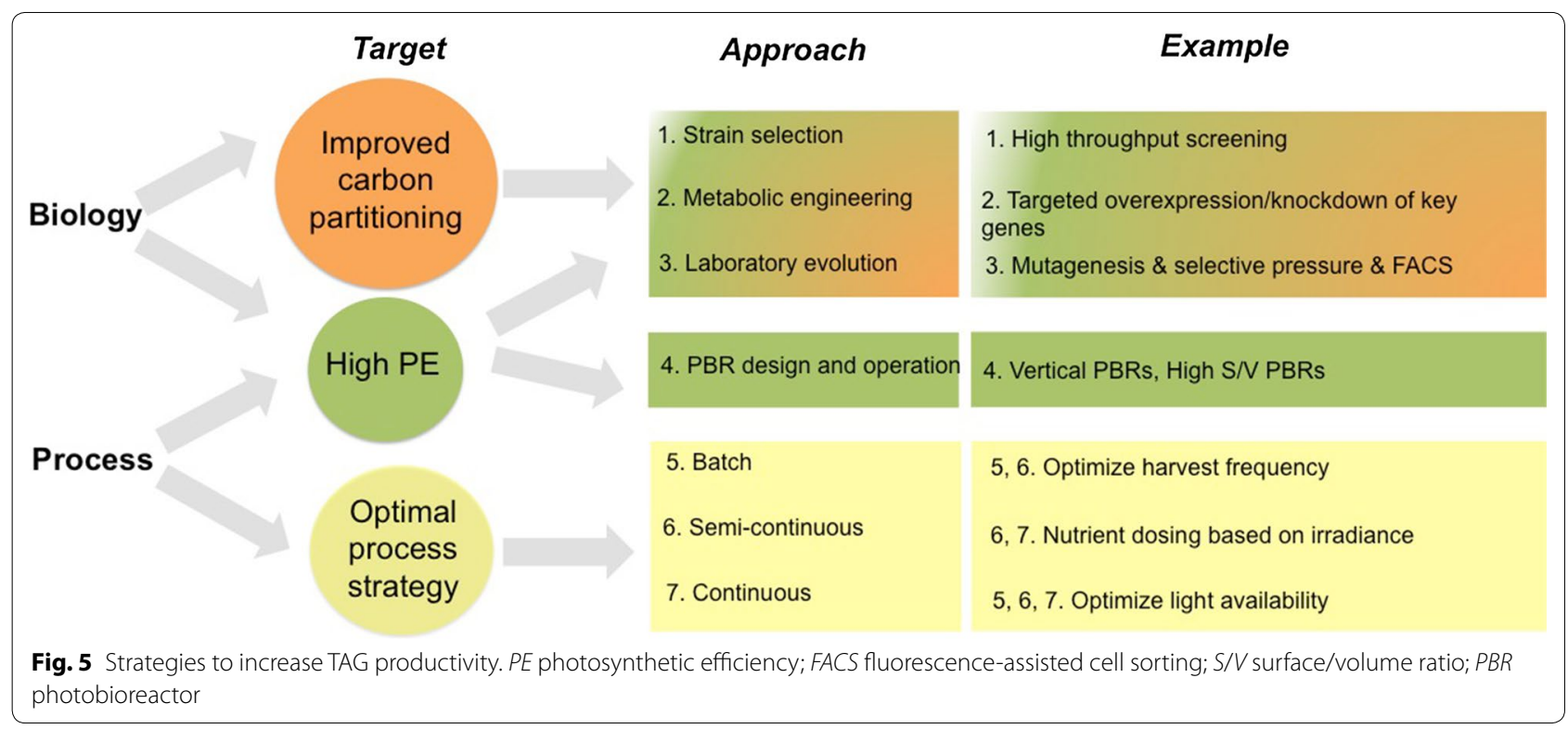


attempts in increasing TAG productivity and/or content have been achieved either by targeted knockdown of a key gene involved in TAG catabolism [45], or by disabling competitive carbon pathways with starchless mutants [23, $46,47]$. Similar results could also be achieved by decreasing the fraction of other biomass components made during $\mathrm{N}$-starvation (e.g. reducing the carbon flow towards polysaccharide and glycoprotein matrix of the cell wall). Besides metabolic engineering, also adaptive laboratory evolution to a selective pressure [48] combined with FACS (Fluorescence Activated Cell Sorting) [38, 49, 50] or RACS (Raman Activated Cell Sorting) [51] can lead to increased TAG productivities.

Higher photosynthetic efficiencies could be achieved by increasing the electron flow through the electron transport chain [52], the activity and specificity of limiting enzymes, e.g. RuBisCo, involved in anabolic pathways $[53,54]$ and also with reduced antenna size mutants $[55$, $56]$.

\section{Process approach for higher TAG productivities}

Optimization of reactor design Much research on developing or improving PBR design is ongoing (e.g. optimal distance between panels/loops, culture depth, mixing times, light distribution in the reactor) [57]. The ideal PBR should intercept all available sunlight while ensuring high photosynthetic efficiencies $[58,59]$ and thus high TAG productivities. This can possibly be achieved with those flat panel designs that allow tilting the reactor to the incoming light (e.g. GWP-III flat panel, F\&M Srl, http:// www.femolnine.it).

In general, for high TAG productivities, PBRs with a high surface-to-volume ratio (e.g. Solix Biofuels ${ }^{\circledR}$ and Proviron Holding NV flat panels and Třeboň, Czech Republic thin-layer cascades ponds) are preferred as, if properly mixed, they ensure high photosynthetic efficiencies and high volumetric TAG concentrations [60-63]. Finally, the selection of optimal designs should be guided by techno-economic analyses considering both biological productivities and production costs associated with each design [13].

Operational strategy: batch vs. (semi-)continuous operations To identify optimal operational strategies for TAG production, much focus has been addressed on the batch vs. (semi-)continuous debate [64-69]. It was shown that a batch process is the most effective strategy for TAG production [14]. This is because batch cultures start with $\mathrm{N}$-replete cells to which a sudden and large energy imbalance is applied (i.e. $\mathrm{N}$-starvation). These cells have a high initial photosynthetic capacity for both biomass and TAG production. Differently, in (semi-)continuous cultures, cells are continuously exposed to limiting conditions, which lead to a lower overall photosynthetic efficiency and productivity compared to batch processes.

\section{Conclusions}

With our techno-economic analysis of a two-step TAG production process in vertically stacked tubular PBRs, we showed that the production costs of TAG-enriched biomass can be substantially decreased by optimizing both process technology and biological performance. Given that TAG productivity is the most influential parameter on production costs, guidelines for achieving higher TAG productivities are discussed in detail. A great potential relies both on strains with enhanced photosynthetic machinery and carbon partitioning towards TAGs and on PBRs able to intercept all sunlight while ensuring high photosynthetic efficiencies. However, high TAG productivities and contents alone do not directly guarantee economic feasibility of the process, when comparing to the present market value of TAGs. Cost-competitiveness strictly relies on the valorization of the whole biomass components and on cheaper PBR designs (e.g. plastic film flat panels). In particular, further research should focus on the development and commercialization of PBRs where active cooling is avoided and stable operating temperatures are maintained by the water basin in which the reactor is placed.

Concluding, with this work we laid down a solid basis for assessing the economic potential of microalgae TAGs and we identified the crucial bottlenecks and future research that is needed to enable profitable and sustainable microalgal TAG production for the commodity markets.

\section{Additional file}

Additional file 1. Model description. A detailed account of the main model features is given

Authors' contributions

GB conceived the study, collected the data, analysed and interpreted the data and wrote the manuscript. JR developed the model, contributed to data interpretation and writing of the manuscript and critically revised the manuscript. PPL and RB contributed to data collection and interpretation and critically revised the manuscript. MJB and RHW coordinated the study, contributed to model development, data interpretation and critically revised the manuscript. All authors read and approved the final manuscript.

\section{Author details}

${ }^{1}$ Bioprocess Engineering, AlgaePARC, Wageningen University, P.O. Box 16, 6700 AA Wageningen, The Netherlands. ${ }^{2}$ Algades-Alga, Development, Engineering and Services, S.L., c. Margaritas, Costa Oeste, El Puerto de Santa María, 11500 Cádiz, Spain. ${ }^{3}$ Biosciences and Aquaculture, Nord University, 8049 Bodø, Norway.

\section{Acknowledgements}

The authors would like to thank the Ministry of Economic Affairs, Agriculture and Innovation and Province of Gelderland, and Biosolar Cells, BASF, BioOils, Cellulac, Drie Wilgen Development, DSM, Exxon Mobil, GEA Westfalia Separator, Heliae, Neste, Nijhuis, Paques, Proviron, Roquette, SABIC, Simris Alg, 
Staatsolie Suriname, Synthetic Genomics, TOTAL and Unilever for the financial support of the AlgaePARC research program.

\section{Competing interests}

The authors declare that they have no competing interests.

\section{Availability of data and materials}

The data sets used and/or analysed during the current study are available from the corresponding author on reasonable request.

\section{Funding}

Ministry of Economic Affairs, Agriculture and Innovation and Province of Gelderland, and Biosolar Cells, BASF, BioOils, Cellulac, Drie Wilgen Development, DSM, Exxon Mobil, GEA Westfalia Separator, Heliae, Neste, Nijhuis, Paques, Proviron, Roquette, SABIC, Simris Alg, Staatsolie Suriname, Synthetic Genomics, TOTAL and Unilever financially supported the AlgaePARC research program and, therefore, the current study. Funding sources did not have any involvement in the study design, data collection, analysis and interpretation and in the writing of the manuscript.

\section{Publisher's Note}

Springer Nature remains neutral with regard to jurisdictional claims in published maps and institutional affiliations.

Received: 19 April 2017 Accepted: 11 July 2017

Published online: 17 July 2017

\section{References}

1. Slocombe S, Benemann J. Microalgal production for biomass and highvalue products. Boca Raton: CRC Press Taylor \& Francis Group; 2016.

2. Paul NP, Tseng CK, Borowitzka M. Aquaculture. West Sussex: Blackwell Publishing Ltd.; 2012.

3. Griffiths M, Harrison STL, Smit M, Maharajh D. Major commercial products from micro- and macroalgae. New York: Springer International Publishing; 2016. p. 269-300.

4. Draaisma RB, Wijffels RH, Slegers PM, Brentner LB, Roy A, Barbosa MJ. Food commodities from microalgae. Curr Opin Biotechnol. 2013;24:169-77.

5. Chisti Y. Biodiesel from microalgae. Biotechnol Adv. 2007;25:294-306.

6. Vanthoor-Koopmans M, Wijffels RH, Barbosa MJ, Eppink MHM. Biorefinery of microalgae for food and fuel. Bioresour Technol. 2013;135:142-9.

7. Malik A, Lenzen M, Ralph PJ, Tamburic B. Hybrid life-cycle assessment of algal biofuel production. Bioresour Technol. 2015;184:436-43.

8. Beal CM, Gerber LN, Sills DL, Huntley ME, Machesky SC, Walsh MJ, Tester JW, Archibald I, Granados J, Greene CH. Algal biofuel production for fuels and feed in a 100-ha facility: a comprehensive techno-economic analysis and life cycle assessment. Algal Res. 2015;10:266-79.

9. Acién FG, Fernández JM, Magán JJ, Molina E. Production cost of a real microalgae production plant and strategies to reduce it. Biotechnol Adv. 2012;30:1344-53.

10. Tredici MR, Rodolfi L, Biondi N, Bassi N, Sampietro G. Techno-economic analysis of microalgal biomass production in a 1-ha Green Wall Panel (GWP ${ }^{\circledR}$ ) plant. Algal Res. 2016;19:253-63.

11. de Vree JH, Bosma R, Janssen M, Barbosa MJ, Wijffels RH. Comparison of four outdoor pilot-scale photobioreactors. Biotechnol Biofuels. 2015;8:215

12. Benvenuti G, Bosma R, Klok AJ, Ji F, Lamers PP, Barbosa MJ, Wijffels RH. Microalgal triacylglycerides production in outdoor batch-operated tubular PBRs. Biotechnol Biofuels. 2015;8:100.

13. Ruiz J, Olivieri G, de Vree J, Bosma R, Willems P, Reith H, Eppink M, Kleinegris DMM, Wijffels RH, Barbosa M. Towards industrial products from microalgae. Energy Environ Sci. 2016;9(10):3036-43.

14. Benvenuti G, Lamers P, Breuer G, Bosma R, Cerar A, Wijfels R, Barbosa M. Microalgal TAG production strategies: why batch beats repeated-batch. Biotechnol Biofuels. 2016;9:64

15. Sousa C, de Winter L, Janssen M, Vermuë MH, Wijfels RH. Growth of the microalgae Neochloris oleoabundans at high partial oxygen pressures and sub-saturating light intensity. Bioresour Technol. 2012;104:565-70.
16. Norsker N-H, Barbosa MJ, Vermuë MH, Wijffels RH. Microalgal productiona close look at the economics. Biotechnol Adv. 2011;29:24-7.

17. Gómez-Pérez CA, Espinosa J, Montenegro Ruiz LC, van Boxtel AJB. CFD simulation for reduced energy costs in tubular photobioreactors using wall turbulence promoters. Algal Res. 2015;12:1-9.

18. Ertit Taştan B, Duygu E, Illbaş M, Dönmez G. Enhancement of microalgal biomass production and dissolved inorganic $\mathrm{C}$ fixation from actual coal flue gas by exogenous salicylic acid and 1-triacontanol growth promoters. Energy. 2016;103:598-604.

19. Bilad MR, Vandamme D, Foubert I, Muylaert K, Vankelecom IFJ. Harvesting microalgal biomass using submerged microfiltration membranes. Bioresour Technol. 2012;111:343-52.

20. Wijffels RH, Barbosa MJ. An Outlook on Microalgal. Biofuels Sci. 2010;329:796-9.

21. Griffiths MJ, Harrison STL. Lipid productivity as a key characteristic for choosing algal species for biodiesel production. J Appl Phycol. 2009;21:493-507.

22. Cuaresma M, Janssen M, Vílchez C, Wijffels RH. Horizontal or vertical photobioreactors? How to improve microalgae photosynthetic efficiency. Bioresour Technol. 2011;102:5129-37.

23. Breuer $G$, de Jaeger $L$, Artus VPG, Martens DE, Springer J, Draaisma RB, Eggink G, Wijffels RH, Lamers PP. Superior triacylglycerol (TAG) accumulation in starchless mutants of Scenedesmus obliquus: (II) evaluation of TAG yield and productivity in controlled photobioreactors. Biotechnol Biofuels. 2014;7:70.

24. Guccione A, Biondi N, Sampietro G, Rodolfi L, Bassi N, Tredici MR. Chlorella for protein and biofuels: from strain selection to outdoor cultivation in a Green Wall Panel photobioreactor. Biotechnol Biofuels. 2014;7:84.

25. Ras M, Steyer JP, Bernard O. Temperature effect on microalgae: a crucial factor for outdoor production. Rev Environ Sci Bio/Technol. 2013;12:153-64.

26. Chauton MS, Olsen Y, Vadstein O. Biomass production from the microalga Phaeodactylum tricornutum: nutrient stress and chemical composition in exponential fed-batch cultures. Biomass Bioenergy. 2013;58:87-94.

27. Rezvani S, Moheimani NR, Bahri PA. Techno-economic assessment of $\mathrm{CO} 2$ bio-fixation using microalgae in connection with three different state-ofthe-art power plants. Comput Chem Eng. 2016;84:290-301.

28. Davis R, Aden A, Pienkos PT. Techno-economic analysis of autotrophic microalgae for fuel production. Appl Energy. 2011;88:3524-31.

29. Breuer G, Lamers PP, Martens DE, Draaisma RB, Wijffels RH. The impact of nitrogen starvation on the dynamics of triacylglycerol accumulation in nine microalgae strains. Bioresour Technol. 2012;124:217-26.

30. Griffiths MJ, Hille RP, Harrison STL. Lipid productivity, settling potential and fatty acid profile of 11 microalgal species grown under nitrogen replete and limited conditions. J Appl Phycol. 2011;24:989-1001.

31. Rodolfi L, Chini Zittelli G, Bassi N, Padovani G, Biondi N, Bonini G, Tredici MR. Microalgae for oil: strain selection, induction of lipid synthesis and outdoor mass cultivation in a low-cost photobioreactor. Biotechnol Bioeng. 2009;102:100-12.

32. San Pedro A, González-López CV, Acién FG, Molina-Grima E. Marine microalgae selection and culture conditions optimization for biodiesel production. Bioresour Technol. 2013;134:353-61.

33. Doan TTY, Sivaloganathan B, Obbard JP. Screening of marine microalgae for biodiesel feedstock. Biomass Bioenerg. 2011;35:2534-44.

34. Taleb A, Pruvost J, Legrand J, Marec H, Le-Gouic B, Mirabella B, Legeret B, Bouvet S, Peltier G, Li-Beisson Y, Taha S, Takache H. Development and validation of a screening procedure of microalgae for biodiesel production: application to the genus of marine microalgae Nannochloropsis. Bioresour Technol. 2015;177:224-32.

35. Benvenuti G, Bosma R, Cuaresma M, Janssen M, Barbosa MJ, Wijffels RH. Selecting microalgae with high lipid productivity and photosynthetic activity under nitrogen starvation. J Appl Phycol. 2014;27:1425-31.

36. Juang Y, Chang J. Applications of microfluidics in microalgae biotechnology: a review. Biotechnol J. 2016;11:327-35.

37. Van Wagenen J, Holdt SL, De Francisci D, Valverde-Pérez B, Plósz BG, Angelidaki I. Microplate-based method for high-throughput screening of microalgae growth potential. Bioresour Technol. 2014;169:566-72.

38. Cabanelas ITD, van der Zwart M, Kleinegris DMM, Barbosa MJ, Wijffels RH. Rapid method to screen and sort lipid accumulating microalgae. Bioresour Technol. 2015;184:47-52. 
39. Bajhaiya AK, Dean AP, Driver T, Trivedi DK, Rattray NJW, Allwood JW, Goodacre R, Pittman JK. High-throughput metabolic screening of microalgae genetic variation in response to nutrient limitation. Metabolomics. 2016;12:1-14.

40. Ji Y, He Y, Cui Y, Wang T, Wang Y, Li Y, Huang W, Xu J. Raman spectroscopy provides a rapid, non-invasive method for quantitation of starch in live, unicellular microalgae. Biotechnol J. 2014;9(12):1512-8.

41. Fon-Sing S, Borowitzka MA. Isolation and screening of euryhaline Tetraselmis spp. suitable for large-scale outdoor culture in hypersaline media for biofuels. J Appl Phycol. 2015;28(1):1-14.

42. Bosma R, de Vree JH, Slegers PM, Janssen M, Wijffels RH, Barbosa MJ. Design and construction of the microalgal pilot facility AlgaePARC. Algal Res. 2014;6(partB):160-9.

43. De Bhowmick G, Koduru L, Sen R. Metabolic pathway engineering towards enhancing microalgal lipid biosynthesis for biofuel applicationa review. Renew Sustain Energy Rev. 2015;50:1239-53.

44. Stephenson PG, Moore CM, Terry MJ, Zubkov MV, Bibby TS. Improving photosynthesis for algal biofuels: toward a green revolution. Trends Biotechnol. 2011;29:615-23.

45. Trentacoste EM, Shrestha RP, Smith SR, Glé C, Hartmann AC, Hildebrand M, Gerwick WH. Metabolic engineering of lipid catabolism increases microalgal lipid accumulation without compromising growth. Proc Natl Acad Sci USA. 2013;110:19748-53.

46. Li Y, Han D, Hu G, Sommerfeld M, Hu Q. Inhibition of starch synthesis results in overproduction of lipids in Chlamydomonas reinhardtii. Biotechnol Bioeng. 2010;107:258-68.

47. de Jaeger L, Verbeek RE, Draaisma RB, Martens DE, Springer J, Eggink G, Wijffels RH. Superior triacylglycerol (TAG) accumulation in starchless mutants of Scenedesmus obliquus: (I) mutant generation and characterization. Biotechnol Biofuels. 2014;7:69.

48. Mooij PR, Stouten GR, Tamis J, van Loosdrecht MCM, Kleerebezem R. Survival of the fattest. Energy Environ Sci. 2013;6:3404.

49. Yu S, Zhao Q, Miao X, Shi J. Enhancement of lipid production in lowstarch mutants Chlamydomonas reinhardtii by adaptive laboratory evolution. Bioresour Technol. 2013;147:499-507.

50. Cabanelas ITD, van der Zwart M, Kleinegris DMM, Wijffels RH, Barbosa MJ. Sorting cells of the microalga Chlorococcum littorale with increased triacylglycerol productivity. Biotechnol Biofuels. 2016;9:183.

51. Wang T, Ji Y, Wang Y, Jia J, Li J, Huang S, Han D, Hu Q, Huang WE, Xu J. Quantitative dynamics of triacylglycerol accumulation in microalgae populations at single-cell resolution revealed by Raman microspectroscopy. Biotechnol Biofuels. 2014;7(1):58

52. Chida H, Nakazawa A, Akazaki H, Hirano T, Suruga K, Ogawa M, Satoh T, Kadokura K, Yamada S, Hakamata W, Isobe K, Ito T, Ishii R, Nishio T, Sonoike K, Oku T. Expression of the algal cytochrome c6 gene in Arabidopsis enhances photosynthesis and growth. Plant Cell Physiol. 2007:48:948-57.

53. Atsumi S, Higashide W, Liao JC. Direct photosynthetic recycling of carbon dioxide to isobutyraldehyde. Nat Biotechnol. 2009;27:1177-80.

54. Lin MT, Occhialini A, Andralojc PJ, Parry MAJ, Hanson MR. A faster Rubisco with potential to increase photosynthesis in crops. Nature. 2014;513:547-50.
55. Melis A. Solar energy conversion efficiencies in photosynthesis: minimizing the chlorophyll antennae to maximize efficiency. Plant Sci. 2009;177:272-80.

56. Kirst $\mathrm{H}$, Formighieri $\mathrm{C}$, Melis A. Maximizing photosynthetic efficiency and culture productivity in cyanobacteria upon minimizing the phycobilisome light-harvesting antenna size. Biochim Biophys Acta-Bioenerg. 2014;1837:1653-64

57. Zittelli GC, Biondi N, Rodolfi L, Tredici MR. Photobioreactors for mass production of microalgae. Oxford: Wiley; 2013

58. Posten C. Design principles of photo-bioreactors for cultivation of microalgae. Eng Life Sci. 2009:9:165-77.

59. Pruvost J, Cornet J-F, Pilon L. Large-scale production of algal biomass: photobioreactors. In: Bux F, Chisti Y, editors. Algae biotechnology, green energy and technology. Switzerland: Springer; 2016. p. 41-66.

60. Masojídek J, Kopecký J, Giannelli L, Torzillo G. Productivity correlated to photobiochemical performance of Chlorella mass cultures grown outdoors in thin-layer cascades. J Ind Microbiol Biotechnol. 2011;38:307-17.

61. Quinn JC, Yates T, Douglas N, Weyer K, Butler J, Bradley TH, Lammers PJ. Nannochloropsis production metrics in a scalable outdoor photobioreactor for commercial applications. Bioresour Technol. 2012;117:164-71.

62. Jerez CG, Enrique N, Malpartida I, Rico RM, Masojídek J, Abdala R, Figueroa FL. Hydrodynamics and photosynthesis performance of Chlorella fusca grown in a thin-layer cascade (TLC) system. Aquat Biol. 2014;22(Chisti 2007):111-22.

63. Masojídek J, Sergejevová M, Malapascua JR, Kopecký J. Thin-layer systems for mass cultivation of microalgae: flat panels and sloping cascades. In: Prokop, A., Bajpai, R.K., Zappi, M.E. (eds.) Algal biorefineries. Cham: Springer International Publishing; 2015. p. 237-261.

64. Klok AJ, Martens DE, Wijffels RH, Lamers PP. Simultaneous growth and neutral lipid accumulation in microalgae. Bioresour Technol. 2013;134:233-43

65. Bona F, Capuzzo A, Franchino M, Maffei ME. Semicontinuous nitrogen limitation as convenient operation strategy to maximize fatty acid production in Neochloris oleoabundans. Algal Res. 2014;5:1-6.

66. San Pedro A, González-López CV, Acién FG, Molina-Grima E. Outdoor pilot-scale production of Nannochloropsis gaditana: influence of culture parameters and lipid production rates in tubular photobioreactors. Bioresour Technol. 2014;169:667-76.

67. Wen X, Geng Y, Li Y. Enhanced lipid production in Chlorella pyrenoidosa by continuous culture. Bioresour Technol. 2014;161:297-303.

68. Fuentes-Grünewald C, Bayliss C, Zanain M, Pooley C, Scolamacchia M, Silkina A. Evaluation of batch and semi-continuous culture of Porphyridium purpureum in a photobioreactor in high latitudes using fourier transform infrared spectroscopy for monitoring biomass composition and metabolites production. Bioresour Technol. 2015;189:357-63.

69. Benvenuti G, Bosma R, Ji F, Lamers P, Barbosa M, Wijffels R. Batch and repeated-batch microalgal TAG production in lab-scale and outdoor photobioreactors. J Appl Phycol. 2016;28(6):3167-77.

\section{Submit your next manuscript to BioMed Central and we will help you at every step:}

- We accept pre-submission inquiries

- Our selector tool helps you to find the most relevant journal

- We provide round the clock customer support

- Convenient online submission

- Thorough peer review

- Inclusion in PubMed and all major indexing services

- Maximum visibility for your research

Submit your manuscript at www.biomedcentral com/submit 